\title{
The Effect Of Static And Dynamic Warm-Up Protocols On Fitness Component And Body Fat Percentage Of Athletes İn Different Branches
}

\author{
Nevzat DEMİRCi ${ }^{*}$, Pervin TOPTAŞ DEMIIRC ${ }^{2}$ \\ ${ }^{1}$ High school of Physical Education and Sports, Mersin University, Turkey \\ ${ }^{2}$ Erdemli Department of Tourism Animation, Mersin University, Turkey \\ *Corresponding author: nevzatdemirci44@ hotmail.com
}

\section{Abstract}

The aim of this study is to investigate the effects of static and Warm-Up Protocols On Fitness Component and body fat percentage of athletes in different branches. In this study, 50 (25 female and 25 male) athletes from Mersin University High School of Physical Education and Sports volleyball, football, basketball, wrestling and handball branches were formed the sample group of the research. The anthropometric characteristics of the individuals Height and weight measurements were made to determine and body fat percentages were determined by Bioelectrical Impedance Analysis. As engine performance tests, Vertical jump test, Sprint performance test $(20 \mathrm{~m})$, sit- reach flexibility test were applied. One-way analysis of variance (ANOVA) was performed to determine whether there was a statistically significant difference between measurements. Data was tested for normality with the "Kolmogorov Smirnov Test". Kruskall Wallis tests were used for comparison among five groups. According to our findings no significant difference was observed between the male branches in terms of body fat percentage $(\% \mathrm{BF})$. Female soccer players were found to have the least body fat percentage when compared to other branches $(\mathrm{p}<0.01)$. Static and dynamic warming protocols it was found to have an effect statistically significant $(\mathrm{p}<0.05, \mathrm{P}<0.001)$ in sit- reach flexibility, vertical jump and speed test values of athletes in different branches. As a result; it has been found that the static and dynamic warming protocolshave different effects in terms of the different sports branches and motor performance parameters. When both male and female performance values were examined, dynamic heating was found to be more dominant. It can be said that the physical and physiological values of the athletes are directly related to the performance of being suitable for the sports branch involved. For this reason, the use of warming protocols is recommended with regard to the results of the study presented here
\end{abstract}

\section{Keywords}

Sports Branches, Body Fat Percentage, static and dynamic Warm-Up

\section{INTRODUCTION}

Among atheletes, warm-up exercises made before a violent exercise specific to the sport branch are one of the generally accepted activities. Most athletes, especially those who will do exhausting exercises, should devote some of their program to warming up (Harmanc1 et al., 2014). Warm-up is regularly used by athletes dealing with different sports branches to gain high performance and prevent injuries during a competition or training session. Ideal body components vary in different sports branches (Sotiropoulos et al., 2010). Ideal body components vary in different sports branches. However, the main purpose is based on low fat and better performance. A high body fat ratio can also result in reduced strength, agility, speed and flexibility, as well as loss of energy. Body weight means the speed, durability and strength of the athletes; Whereas the body composition can affect the athlete's power, appearance and agility (Akin et al., 2004). Decrease in the performance of the athletes is related to body composition factors such as body fat percentage, body mass index and body mass. There is a close relationship between factors determining body composition and aerobic and cardiovascular health. With a decrease in body fat, the aerobic condition increases (Bowers ve Fox, 1988). Recent research has shown that even in physically active men with the most appropriate lifestyle, It has been suggested that lower BMI is associated with greater risk for vascular disease 
(Brooks, 2002). In general, body proportions of body fat and fat rates are examined (Poyraz ve Demirkan, 2011; Zorba, 2005). The body fat ratio accounts for $15 \%$ to $17 \%$ of body weight in adult males and $25 \%$ in females. The performance difference between the sportsmen can be explained by the excess of fat in the body of women. Therefore, women who run long distance or endurance sports seem to have less than $10 \%$ body fat (Fox, Bowers ve Foss, 1999 ).

In athletes body composition is a conditioning factor that affects performance (Leão et al., 2017; Copic et al., 2014). Even small changes in body fat percentage can be a major influence on the ability to perform anaerobic movements (Inacio et al., 2011). Assessment of body composition can provide valuable information about changes that the athlete observes throughout the season (Kyle et al., 2003). Moreover, incorrectly assessing body composition can cause difficulties in giving a proper nutrition plan because of the pressure to reach a target body fat value (Fink \& Mikesky, 2015). Assessment of body composition is of particular importance with respect to percent body fat, which is the most valuable parameter for sportsmen or coaches to determine the best composition of the body (Hogstrom et al.,2012; Malina, 2007). In recent years, static stretching exercises have become one of the most important parts of the warm-up period. Traditional warming aims to increase body temperature by $1-2$ degrees with submaximal exercises (running, cycling); to increase the rate of nerve conduction, enzymatic loop and muscle compliance. The second component of the warming constitutes a static stretch made by waiting for 15 to 60 seconds at the pain limit at the end of the joint's range of motion on the target extremity. Dynamic warming usually involves controlled movements of the muscle group of the warm-up exercise, with the contraction of the antagonist muscles, without compromising the normal limits of joint range of motion (Şerefoğlu, 2016).

Stretching exercises are important to increase the performance and stretching ability of the athlete. These exercises need to be done regularly during both warmup and training. In many studies discussing the effect of stretching exercises on the prevention of performance and injury, it is concluded that stretching exercises are important in the pre-activation period (McNeal and Sands 2003; Turan and Cilli, 2016). Warm-up exercises allow the athlete to be ready for competition and reduce the risk of injury to the muscles and joints through applied exercises. Warm-up exercises usually start at a low level and gradually increase. After these economical conditions of low density, static stretching exercises are made. Recent studies, however, have shown that these exercises have prevented the athletes from getting real performances (Turan and Çilli, 2016). Also in some studies; They recommended that dynamic exercises improve performance and prepared for performance (Fletcher et al., 2007). The aim of this study is to investigate the effects of static and dynamic Warm-Up Protocols On Fitness Component and body fat percentage of athletes in different branches.

\section{MATERIALS AND METHODS}

\section{Participants}

A total of 50 national male and female athletes sporting in the elite level took part inthe study. This study was carried out from students who are studying at Mersin University Physical Education and Sports School and who are doing healthy volleyball, soccer, basketball, wrestling and handball branches including female $(n=25)$ and male $(\mathrm{n}=25)$. A warm-up protocol was applied prior to each performance test measurement. Warm-up protocols were started with a 5-minute low-tempo aerobic run. static and dynamic warm-up were performed separately for each performance test with a search of 48 hours. The legal permissions required for the study were taken and firstly the athlete was informed in detail about the test before starting the test. In addition, the athletes have signed an enlightened form to show that they volunteered to work before joining this work. The athletes participating in the study were informed that they should not consume any food at least 4 hours before, consume liquid as much as they drink, do not take diuretics within one week of the measurements, do not consume substances such as caffeine and alcohol 12 hours before and do not exercise 6 hours before the measurements (Heyward, 1996). 


\section{Procedure}

\section{Static Warming}

In addition to the 5 min running, static stretching movement was applied 8 times to the upper and lower extremity muscles. Static warm-up; applied from a slow stretching to a taut sensitivity level at the threshold of pain. The warm-up 30 seconds twice for stretching, 15 seconds rest intervals were applied after each section. Static warm-up exercises were applied separately to the right and left extremities (Alter, 1998).

\section{Dynamic Warming}

In addition to the 5 min running, static stretching movement was applied 8 times to the upper and lower extremity muscles. Dynamic stretching exercises, 2 times $30 \mathrm{sec}$ and $15 \mathrm{sn}$ rest intervals between repetitions $15 \mathrm{~m}$ the violence was applied in the increasing manner of the field. The subjects were watched by the researchers in order to make the movements desired (Joggers et.al., 2008).

\section{Anthropometric Measurements and Performance Tests}

Body mass index (BMI) of subjects participating in the study was calculated as $\mathrm{kg} /$ boy $^{2}$. Body Mass Index = Body Weight $(\mathrm{kg}) /$ Length $\left(\mathrm{m}^{2}\right)$. Height and weight measurements were made to determine the anthropometric characteristics of the participants and body fat percentages were determined by Bioelectrical Impedance Analysis (Tanita 62 418-MA Japan). Anthropometric measurements were made by the same person on the first day of measurement. Body weight (BW); Subjects were printed in standard sportswear (shorts, athletes) with no shovels \pm 0.1 error ( $\mathrm{T}$ Tanita 418- MA Japan), height; The distance between the head and the vertex of the head following a deep inspiration was measured with a stadiometer (Holtain Ltd. U.K.) \pm $1 \mathrm{~mm}$ error. Electrodes on the scales with bare feet from the subjects were asked to stand on the screen until they reached the bottom of the analyzer in such a way that they would come into contact with the soles of the feet and in a steady position and without motion. (\%BF) and impedance data were recorded.

\section{Sit-Reach Flexibility Test}

For the measurements, a Sit and Reach stand with a length of $35 \mathrm{~cm}$, a width of $45 \mathrm{~cm}$ and a height of $32 \mathrm{~cm}$ was used. The test was repeated 3 times and the best result was considered to be the value of flexibility (Kürkçü ve ark, 2009).

\section{$20 \mathrm{~m}$. Speed Test}

The aim is to determine speed. The participant run $20 \mathrm{~m}$ at a maximum speed of $20 \mathrm{~m}$. The running time is saved in seconds with the stopwatch. The best results were recorded by repeating the test twice (Ayan and Mülazoğlu, 2009).

\section{Vertical Jump Test}

Vertical bounce measurement will be applied with a flat and high-point marking method. Athletes will be asked to stand on the side as if they are adjacent to the wall, their middle fingers wetted in a pack of water glasses, and they will be asked to leave a trace at the furthest distance they can reach without heels rising upwards. The athletes will be asked to wet their fingers again and will be asked to leave a second mark at the furthest point by leaping up from where they are. The distance between these two tracks will be measured with the aid of the meter, vertical jumps of the athletes will be noted. The test will be tried three times and will be included in the best score calculation.

\section{Statistical Analysis}

Statistical evaluation was done with SPSS 22.0 computer program. One-way analysis of variance (ANOVA) was performed to determine whether there was a statistically significant difference between measurements. Mann Whitney U test was used for paired comparisons because the data did not have normal distribution. Between the data. 0.05 , values were considered significant. 


\section{RESULTS}

Physical and anthropometric characteristics of male and female athletes related to age, height, body mass index, body fat index and body fat percentage were determined from different branches participating in the study (Table 1 and Table 2). According to physical and anthropometric measurements of male athletes in sports activities in different sports branches (Table
1); basketball and soccer players' body height and body weight were significantly different when compared to other sports branches ( $\mathrm{p}<0.05, \mathrm{p}$ $<0.01)$. Volleyball players' BMI was found to be lower than other branches ( $\mathrm{p}<0.05$ ), but there was no significant difference in body fat percentage among the branches.

Table 1. Comparison of demographic and anthropometric values of male athletes in different branches

\begin{tabular}{llllll}
\hline \multirow{2}{*}{ Parametres } & Handball & Voleyball & Wrestling & Basketball & Soccer \\
\cline { 2 - 6 } & $\begin{array}{l}\text { Male (5) } \\
\mathbf{X} \pm \text { SD }\end{array}$ & $\begin{array}{l}\text { Male (5) } \\
\mathbf{X} \pm \text { SD }\end{array}$ & $\begin{array}{l}\text { Male (5) } \\
\mathbf{X} \pm \text { SD }\end{array}$ & $\begin{array}{l}\text { Male (5) } \\
\mathbf{X} \pm \text { SD }\end{array}$ & $\begin{array}{l}\text { Male (5) } \\
\text { X } \pm \text { SD }\end{array}$ \\
\cline { 2 - 6 } Age (Year) & $21,40 \pm 1,43$ & $21,60 \pm 1,09$ & $20,20 \pm 2,68$ & $18,80 \pm 0,83$ & $23,00 \pm 1,24$ \\
\hline $\begin{array}{l}\text { Body Height } \\
\text { (cm) }\end{array}$ & $1,75 \pm 0,05$ & $1,79 \pm 0,04$ & $1,71 \pm 0,05$ & $1,89 \pm 0,04^{* *}$ & $1,85 \pm 0,04 *$ \\
\hline $\begin{array}{l}\text { Body } \\
\text { Weight(kg) }\end{array}$ & $73,52 \pm 10,07$ & $75,20 \pm 4,99$ & $72,88 \pm 10,40$ & $78,80 \pm 8,92^{*}$ & $82,52 \pm 5,56^{* *}$ \\
\hline $\begin{array}{l}\text { Body Mass } \\
\text { İndex(BMI) }\end{array}$ & $23,76 \pm 2,82$ & $19,20 \pm 10,80^{*}$ & $24,98 \pm 2,72$ & $22,00 \pm 3,22$ & $24,68 \pm 1,17$ \\
\hline & & & & \\
$(\%$ BFP) & $12,60 \pm 8,46$ & $12,90 \pm 5,06$ & $13,82 \pm 3,79$ & $13,24 \pm 6,82$ & $13,22 \pm 3,74$ \\
\hline
\end{tabular}

BH: Body Height, (\% BFP): Body Fat Percentage, BW: Body Weight, BMI: Body Mass Index, * significant difference at $\mathrm{p}<.05$ level. ** significant difference at $\mathrm{p}<.01$ level.

According to the results of physical and anthropometric measurements of female athletes in sports activities in different sport branches (Table $2)$; the shortest wrestlers were and the tallest was determined as the footballers $(\mathrm{p}<0.05)$. In terms of body weight, it was observed that the volleyball players were high and Soccer players were significantly lower than the other branches ( $p$ $<0.05, \mathrm{p}<0.01)$. Soccer players were found to have the least body fat percentage when compared to other branches $(\mathrm{p}<0.01)$.

Table 2. Comparison of demographic and anthropometric values of female athletes in different branches

\begin{tabular}{lccccc}
\hline \multirow{2}{*}{ Parametres } & Handball & Voleyball & Wrestling & Basketball & Soccer \\
\cline { 2 - 6 } & $\begin{array}{c}\text { Female (5) } \\
\mathbf{X} \pm \text { SD }\end{array}$ & $\begin{array}{c}\text { Female (5) } \\
\mathbf{X} \pm \text { SD }\end{array}$ & $\begin{array}{c}\text { Female (5) } \\
\mathbf{X} \pm \text { SD }\end{array}$ & $\begin{array}{c}\text { Female (5) } \\
\mathbf{X} \pm \text { SD }\end{array}$ & $\begin{array}{c}\text { Female (5) } \\
\mathbf{X} \pm \text { SD }\end{array}$ \\
\hline $\begin{array}{l}\text { Age (Year) } \\
\text { Body Height } \\
\text { (cm) }\end{array}$ & $1,40 \pm 1,51$ & $21,80 \pm 1,64$ & $20,80 \pm 2,04$ & $20,80 \pm 1,64$ & $19,80 \pm 1,09$ \\
\hline $\begin{array}{l}\text { Body } \\
\text { Weight(kg) }\end{array}$ & $54,28 \pm 5,21$ & $64,10 \pm 11,38^{*}$ & $57,72 \pm 5,61$ & $61,28 \pm 9,29$ & $50,78 \pm 5,31^{* *}$ \\
\hline $\begin{array}{l}\text { Body Mass } \\
\text { Index(BMI) }\end{array}$ & $19,78 \pm 0,89$ & $21,06 \pm 2,28$ & $21,62 \pm 1,56$ & $20,60 \pm 1,71$ & $19,20 \pm 1,79$ \\
\hline & & & & & \\
$(\%$ BFP) & $21,22 \pm 6,81$ & $23,74 \pm 6,98$ & $21,48 \pm 3,38$ & $23,68 \pm 6,48$ & $18,52 \pm 5,55^{* *}$ \\
\hline
\end{tabular}

BH: Body Height, (\% BFP): Body Fat Percentage, BW: Body Weight, BMI: Body Mass Index, * significant difference at $\mathrm{p}<.05$ level. $* *$ significant difference at $\mathrm{p}<.01$ level.

It has been determined that dynamic warming has a statistically significant difference on the $20 \mathrm{~m}$ speed test values in sportsmen in different branches participating in the study. According to this, it was determined that the dynamic warming effect of wrestling, basketball and soccer values in men was significant ( $\mathrm{p}<0.05, \mathrm{p}<0.001)$. In women; handball, wrestling and soccer values were 
found to be significantly different in favor of dynamic warming $(\mathrm{p}<0.05)$ (Table 3).

Table 3. Comparison of $20 \mathrm{~m}$ speed test values Static and Dynamic warming methods of athletes participating in the study

\begin{tabular}{|c|c|c|c|c|c|c|c|c|}
\hline \multirow[b]{2}{*}{ Variables } & \multicolumn{4}{|c|}{ MALE } & \multicolumn{4}{|c|}{ FAMALE } \\
\hline & Group & $\mathbf{N}$ & $\mathbf{M}$ & SD & Sig. & $\mathbf{M}$ & SD & Sig. \\
\hline \multirow{2}{*}{ Handball } & Static & 5 & 2,99 & 0,09 & \multirow{2}{*}{, 134} & 3,48 & 0,03 & \multirow{2}{*}{, $031^{*}$} \\
\hline & Dynamic & 5 & 2,95 & 0,10 & & 3,40 & 0,02 & \\
\hline \multirow{2}{*}{ Voleyball } & Static & 5 & 3,08 & 0,12 & \multirow{2}{*}{, 250} & 3,99 & 0,07 & \multirow{2}{*}{,115 } \\
\hline & Dynamic & 5 & 3,02 & 0,08 & & 3,95 & 0,04 & \\
\hline \multirow{2}{*}{ Wrestling } & Static & 5 & 3,10 & 0,13 & \multirow{2}{*}{, $001 * *$} & 3,75 & 0,09 & \multirow{2}{*}{, $034^{*}$} \\
\hline & Dynamic & 5 & 2,90 & 0,04 & & 3,66 & 0,13 & \\
\hline \multirow{2}{*}{ Basketball } & Static & 5 & 3,02 & 0,09 & \multirow{2}{*}{, $010^{*}$} & 3,75 & 0,06 & \multirow{2}{*}{,215 } \\
\hline & Dynamic & 5 & 2,90 & 0,05 & & 3,71 & 0,05 & \\
\hline \multirow{2}{*}{ Soccer } & Static & 5 & 3,08 & 0,12 & \multirow{2}{*}{, $001 * *$} & 3,62 & 0,13 & \multirow{2}{*}{, $037 *$} \\
\hline & Dynamic & 5 & 2,92 & 0,05 & & 3,55 & 0,09 & \\
\hline
\end{tabular}

It has determined that Satatik and Dynamic Isınman made a statistically significant difference in sit-reach flexibility test values in sportsmen in different branches participating in the study. According to this, it was determined that men had a significant effect of static warming on the handball, dynamic warming on the volleyball and wrestling branches $(\mathrm{p}<0.05, \mathrm{p}<0.001)$. In women athletes; When handball, volleyball and wrestling values were examined, it was determined that there was a significant difference in favor of dynamic warming $(\mathrm{p}<0.05, \mathrm{p}<0.001)$ (Table 4).

Table 4. Comparison of Sit-Reach Flexibility Test values Sattik and Dynamic warming methods of athletes participating in the study

\begin{tabular}{|c|c|c|c|c|c|c|c|c|}
\hline \multirow[b]{2}{*}{ Variables } & \multicolumn{3}{|c|}{ MALE } & \multicolumn{4}{|c|}{ FAMALE } & \multirow[b]{2}{*}{ Sig. } \\
\hline & Group & $\mathrm{N}$ & M & $\mathrm{SD}$ & Sig. & $\mathrm{M}$ & $\mathrm{SD}$ & \\
\hline \multirow{2}{*}{ Handball } & Static & 5 & 23,65 & 532 & \multirow{2}{*}{, $038 *$} & 25,20 & 4,30 & \multirow{2}{*}{, $025^{*}$} \\
\hline & Dynamic & 5 & 21,25 & 4,70 & & 27,50 & 7,30 & \\
\hline \multirow{2}{*}{ Voleyball } & Static & 5 & 30,65 & 6,11 & \multirow{2}{*}{, 836} & 32,30 & 5,10 & \multirow{2}{*}{, $004 * *$} \\
\hline & Dynamic & 5 & 31,41 & 5,10 & & 35,10 & 4,90 & \\
\hline \multirow{2}{*}{ Wrestling } & Static & 5 & 35,50 & 4,90 & \multirow{2}{*}{, $001 * *$} & 36,40 & 4,95 & \multirow{2}{*}{, $002 * *$} \\
\hline & Dynamic & 5 & 37,67 & 4,50 & & 39,30 & 4,30 & \\
\hline \multirow{2}{*}{ Basketball } & Static & 5 & 25,86 & 7,50 & \multirow{2}{*}{,362 } & 30,60 & 5,30 & \multirow{2}{*}{, 345} \\
\hline & Dynamic & 5 & 26,33 & 7,32 & & 31,00 & 5,10 & \\
\hline \multirow{2}{*}{ Soccer } & Static & 5 & 29,9 & 4,05 & \multirow{2}{*}{, 056} & 30,40 & 4,10 & \multirow{2}{*}{, 370} \\
\hline & Dynamic & 5 & 30,7 & 5,31 & & 31,20 & 5,15 & \\
\hline
\end{tabular}

A statistically significant difference was found in the dynamic warming test values of dynamic heat in the sportsmen in the different branches participating in the study. According to this, it was determined that dynamic warming in handball, volleyball, football and basketball branches of athletes in men and women was significant $(\mathrm{p}<0.05, \mathrm{p}<0.001)$ (Table 5). 
Table 5. Comparison of Vertical Jump Test values Sattik and Dynamic warming methods of athletes participating in the study

\begin{tabular}{|c|c|c|c|c|c|c|c|c|}
\hline \multirow[b]{2}{*}{ Variables } & \multicolumn{3}{|c|}{ MALE } & \multicolumn{4}{|c|}{ FAMALE } & \multirow[b]{2}{*}{ Sig. } \\
\hline & Group & $\mathbf{N}$ & $\mathbf{M}$ & SD & Sig. & $\mathbf{M}$ & SD & \\
\hline \multirow{2}{*}{ Handball } & Static & 5 & 50,65 & 6,17 & \multirow{2}{*}{, $034 *$} & 47,65 & 6,17 & \multirow{2}{*}{, $025^{*}$} \\
\hline & Dynamic & 5 & 55,70 & 6,19 & & 52,05 & 4,81 & \\
\hline \multirow{2}{*}{ Voleyball } & Static & 5 & 55,60 & 5,50 & \multirow{2}{*}{, $050^{*}$} & 45,92 & 6,14 & \multirow{2}{*}{, $014 *$} \\
\hline & Dynamic & 5 & 60,02 & 5,70 & & 50,01 & 7,68 & \\
\hline \multirow{2}{*}{ Wrestling } & Static & 5 & 45,30 & 5,20 & \multirow{2}{*}{,622 } & 36,20 & 6,90 & \multirow{2}{*}{, 534} \\
\hline & Dynamic & 5 & 47,05 & 4,40 & & 37,40 & 7,10 & \\
\hline \multirow{2}{*}{ Basketball } & Static & 5 & 52,20 & 4,80 & \multirow{2}{*}{,001** } & 47,90 & 4,30 & \multirow{2}{*}{, $001 * *$} \\
\hline & Dynamic & 5 & 59,40 & 5,80 & & 55,80 & 5,52 & \\
\hline \multirow{2}{*}{ Soccer } & Static & 5 & 50,30 & 7,50 & \multirow{2}{*}{, $041 *$} & 45,60 & 5,20 & \multirow{2}{*}{, $037 *$} \\
\hline & Dynamic & 5 & 55,80 & 5,60 & & 48,50 & 4,40 & \\
\hline
\end{tabular}

\section{DISCUSSION AND CONCLUSION}

The aim of this study is to investigate the effects of static and dynamic warming protocols on some motor tests and body fat percentage of athletes in different branches. In our study, significant differences were found between boys 'basketball and footballers' height $(1,89 \pm 0,04$; $1,85 \pm 0,04)$ and body weight $(78,80 \pm 8,92 ; 82,52$ $\pm 5,56)$. BMI $(19,20 \pm 10,80)$ of the volleyball players was lower than the other branches, but no significant difference was found between the branches in terms of body fat percentage. For female athletes, the shortest wrestlers $(1.63 \pm 0.06)$ and the tallest soccer players $(1.76 \pm 0.02)$ were determined. In terms of body weight, the volleyball players $(64,10 \pm 11,38)$ were significantly higher and soccer players $(50,78 \pm$ 5,31 ) were significantly lower when compared to the other branches. On the other hand, it was determined that footballers had the least percentage of body fat $(18,52 \pm 5,55)$ when compared to other branches.

In a study done (Duyul Albay et al., 2008). Volleyball and handball; Between handball and soccer, volleyball and soccer branches $(p<0.01)$ and in the mean values of total body fat percentage; Handball and volleyball, handball and soccer branches $(p<0.05)$ there was a statistically significant difference in the level. In a similar study, Tsunawake et al. (1995) found that body fat percentage of volleyball women was $18 \%$. Although the minimum percentage of body fat is aimed at in general of sports branches, today body fat ratios show differences between branches (Üstündal and Köker, 1998). In another study; Duncan et al. (2006) reported a body fat percentage of 12.17 for elite male volleyball players. Body fat percentage is considered an important element of sporty performance. It is suggested that there is an important relationship between fat percentage and performance criteria in many different sports branches. However, when studies on sportsmen were conducted, different results were obtained depending on the sport, age, performance level and population (Açıkada et al., 1991).

Miller et al. (2002) suggested that a $4 \% \mathrm{lb}$ increase in athletic body fat tended to decrease during the season over athletic performance. For this reason, it is common practice to expect a change in body weight, especially fat mass, in response to training and dietary interventions (Hammami et al., 2013). Obtaining a specific body composition for a species is directly related to individual performance and is now seen as a major challenge to individualize and periodize the development process of the athlete (Thomas, 2016). Therefore, the reduction in the exercise capacity of athletes affects body composition factors (body fat percentage, body mass index, and body mass). Body composition factors have close associations and aerobic, cardiovascular health provides an increase in aerobic fitness with reduced body fat (Brooks, 2002). Çon et al. (2012) In a study of 20 female and 20 male learners to 
determine the effect of flexibility and body fat percentage on vertical jump performance, the relationship between vertical jump performance and body fat percentage of female volleyballs was statistically insignificant, positively contributing to vertical jump performance of flexibility, Whereas increase in percent body fat affects flexibility in the negative direction. In another study by Falk et al. (1996), for all sports branches, including anaerobic or aerobic work, the excess of fat in the body and thus the low mass of lean muscle mass is negatively affecting performance. Excessive amounts of body fat may result in inadequate caloric and oxygen expenditure for an activity as desired. This means lower performance. Moreno et al. (2004), in studythere was no significant difference in the BMI among the sportsmen and control groups in sporting activities in the football field. However, it was determined that the body fat percentage values of the control group were lower than those of the soccer players. These notifications support our findings. In a similar study, Dueck et al. (1996) suggested that the increased amount of fat in the athletes dealing with basketball and handball sports branches had negative effects on balance and coordination.

In our study; Static and dynamic warming protocols it was found to have an effect statistically significant ( $p<0.05, P<0.001)$ in sitreach flexibility, vertical jump and speed test values of athletes in different branches. As a result; it has been found that the static and dynamic warming protocolshave different effects in terms of the different sports branches and motor performance parameters. Ünlü (2008) investigated the acute effects of combined warming practices (static and dynamic) on anaerobic power performance. After the application, the children performed a sit-reach flexibility test, a vertical jump and a $20 \mathrm{~m}$ speed test after each warm-up. It is observed that the dynamic warming exercises applied to children have a positive effect on $20 \mathrm{~m}$ speeding, vertical jump, agility and 1sit-reach flexibility test performance. Alikhajeh et al. (2012) conducted a study of selected motor performance measurements of 20 male elite soccer players in terms of different warming protocols. Static and dynamic warm-up application with $20 \mathrm{~m}$. They were intended to measure their speed. At the end of the study it was stated that the best result was the dynamic warming protocol. In this context, it can be said that the findings obtained on the effect of different warming protocols on sprint performance are similar to the results of our study.

Saoulidis et al. (2010) In study investigated the acute effect of static and dynamic warming on $20 \mathrm{~m}$ sprint performance in elite handballs aged 1925 years. They found that static stretching exercises did not affect $20 \mathrm{~m}$ sprint performance. Knudson et al. (2004) investigated the acute effect of tennis sports on speed performance in a study of 83 tennis players. At the end of the study, they found that the static warming exercises did not change the speed performance. Therefore, it is thought to be due to the changes in the muscletendon unit resulting from as a description of the non-effect of the static germane on the speed performance. Ryan et al. (2014) found that in their study investigate the acute effects of 22 male athletes on vertical jump performance, flexibility and muscle fatigue of dynamic stresses in different volumes. As a result, sit-reach flexibility test values increased in all conditions ( $\mathrm{p}<0.01)$. Gelen (2008) in their study measured the acute effect of static and dynamic warming exercises on the vertical jump performance of 56 students in the Department of Physical Education and Sports. As a result of the measurements, the dynamic warmup exercises increased the performance.

\section{Conclusion}

According to the results of this study; There was no significant difference in body fat percentage among male athletes. In female athletes, footballers were found to have the least percentage of body fat when compared to other branches. While there was a significant relationship between BMI, VYY, VA and BH values of male and female athletes, it was found that the relationship between BMI and BH was not significant in males. According to findings, balanced body composition is very important for sportsmen in different branches; The lower level of fat and the higher muscle mass have a significant effect on the physical performance of the athletes. For this reason, it can be said that the athletes' body composition values are directly related to the performance of being suitable for the sports field involved. This type of studies can be made clear when considering the number of participants and values related to VYY specific to different branches can be clearly shown. Static and dynamic warming protocols it was found to have an effect 
statistically significant in sit- reach flexibility, vertical jump and speed test values of athletes in different branches. As a result; it has been found that the static and dynamic warming protocolshave different effects in terms of the different sports branches and motor performance parameters. When both male and female performance values were examined, dynamic heating was found to be more dominant. It can be said that the physical and physiological values of the athletes are directly related to the performance of being suitable for the sports branch involved. For this reason, the use of warming protocols is recommended with regard to the results of the study presented here. In addition, warm-up exercises should be considered as part of the daily work of different sports branches and should not be neglected.

Acknowledgments: The authors would like to thank to the athletes for their support in collecting data.

Conflict of interests: The author declares that there is no conflict of interests

\section{REFERENCES}

Açıkada C, Ergen E, Alpar R \& Sarpyener K (1991). Investigation of body composition parameters in male athletes.. H.Ü. Journal of Sports Sciences. H.Ü. Spor Bilim Dergisi, 2(2): 1- 25.

Akın G, Özder A, Özet BK \& Gültekin T (2004). Body composition values of elite male athletes. Ankara Üniversitesi Dil ve TarihCoğrafya Fakültesi Dergisi, 44(1):125-134.

Alter MJ (1998). Sport Stretch, Champaign, II Human Kinetics Pub, 58.

Alikhajeh Y, Rahimi NM, Fazeli H, Rahimi RM (2012). Differential stretching protocols during warm-up on select performance measures for elite male soccer players. Procedia-Social and Behavioral Sciences, 46: 1639-1643.

Ayan V \& Mülazimoğlu O (2009). Talent selection in sports and assessment of the physical characteristics and some performance profiles of female children between 8-10 years-old in guidance to sports (ankara sample). Nigde University Journal of Physical Education And Sport Sciences Vol 4, No 3 ..
Brooks LL (2002). The effect of after school physical activity and adult encouragement on adolescent. University of Wisconsin.

Bowers RW \& Fox EL (1988). Sports physiology, 3rd edition, Boston; McGraw Hill.

Burke EJ (1980). Towards and understanding of human performance. Movement Publ. NY.

Copic N, Dopsaj M, Ivanovic J, Nesic G \& Jaric S (2014). Body composition and muscle strength predictors of jumping performance: Differences between elite female volleyball competitors and nontrained individuals. J. Strength Cond. Res. 28: 2709-2716.

Çon M, Akyol P, Tural E, Taşmektepligil MY (2012). The effect of flexibility and body fat percentage on vertical jump performance with volleyball players. Selçuk Unıversity Journal Of Physical Education And Sport Science, 14 (2): 202-207

Dueck CA, Matt KS, Manore M \& Skinner JS (1996). Treatment of athletic amenorrhea with a diet and training intervention program, Int J Sport Nutr, 6:24-40.

Duncan MJ, Woodfield L \& Al-Nakeeb Y (2006). Anthropometric and Physiological characteristics of junior elite volleyball players. British Journal of Sports Medicine, 40: 649-651.

Duyul AM, Tutkun E, Ağaoğlu YS, Canikli A \& Albay F (2008). The investigation of some motor values and antropometric characteristics of handball, volleyball and football university teams. SPORMETRE Journal of Physical Education and Sport Sciences, VI (1) 13-20.

Falk B, Weinstein Y, Dodan R, Abramson DA, Mannsegal D \& Hoffman JR (1996). A treadmill test of sprint running. Scand. J. Med. Sci. Sports, 6: 259- 264.

Fink HH \& Mikesky AE (2015). Practical Applications in Sports Nutrition, 4th ed.; Jones \& Bartlett Learning: New York, NY, USA.

Fletcher IM, Anness R (2007). The Acute Effects of Combined Static and Dynamic Stretch Protocols on FiftyMeter Sprint Performance in Track and Field Athlete, Journal of Strength and Conditioning Research, 21(3), 784-7.

Fox E, Bowers RW \& Foss ML. (1999). Physiological basis of physical education 
and sport. Bağırgan Yayınevi,

(Çeviri: Mesut. Cerit) Ankara, 212-213.

Gelen E (2008). Acute effects of different warmup protocols on vertical jump performance, SPORMETRE Journal of Physical Education and Sport Sciences, VI (4) 207-212.

Hammami MA, Ben Abderrahmane A, Nebigh A, Le Moal E, Ben Ounis O, Tabka Z \& Zouhal H (2013). Effects of a Soccer Season on Anthropometric Characteristics and PhysicalFfitness in Elite Young Soccer Players. J. Sports Sci. 31: 589-596. [CrossRef] [PubMed]

Harmancı H, Karavelioğlu MB, Şentürk A \& Kalkavan A (2014). Effects of different warm-up durations on wingate anaerobic power and capacity results. Sportif Bakış: Spor ve Eğitim Bilimleri Dergisi, 1(1): 4352.

Heyward VH \& Stolarczyk LM (1996). Applied body composition assessment. Champaign, IL: Human Kinetics.

Hogstrom G, Pietila T, NordStrom P \& Nordstrom A (2012). Body composition and performance: Influence of sport and gender among adolescents. J. Strength Cond. Res. 26: 1799-1804. [CrossRef] [PubMed]

Inacio, M., DiPietro, L., Visek, A.J. \& Miller, T.A. (2011). Influence of upper-body external loading on anaerobic exercise performance. J. Strength Cond. Res. 25, 896-902. [CrossRef] [PubMed]

Knudson D, Noffal JG, Bahamonde ER, Bauer AJ, Blackwell RJ (2004). Stretching has no effect on tennis serve performance, J Strength Cond Res; 18(3):654-656.

Kürkçü R, Afyon YA, Yaman Ç \& Özdağ S (2009). Comparison of some physical and physiologic properties of soccer players and badminton players of 10-12 years old group. İnternational Journal of Human Science, 6(1), 547-556.

Kyle UG, Piccoli A \& Pichard C (2003). Body composition measurements: Interpretation finally made easy for clinical use. Curr. Opin. Clin. Nutr. Metab. Care, 387-393. [CrossRef] [PubMed]

Joggers j, Swank A, Frast K, Lee C (2008). The acute effects of dynamic and ballistic stretching on vertical jump height, force, and power. J Strength Cond Res. 22(6):18441849.
Leão C, Simões M, Silva B, Filipe Manuel Clemente FM, Bezerra P \& Camões M (2017). Body composition evaluation 1ssue among young elite football players: DXA Assessment. Sports, 5, 17; doi:10.3390/sports5010017

Malina RM (2007). Body Composition in Athletes: Assessment and Estimated Fatness. Clin. Sports Med. 26, 37-68. [CrossRef] [PubMed]

McNeal J, Sands W (2003). Acute Static Stretching Reduces Lower Extremity in Trained Children, Pediatric Exercise, 15, 139-5.

Miller TA, White ED, Kinley KA, Congleton JJ \& Clark MJ (2002). The effects of training history, player position, and body composition on exercise performance in collegiate football players. J Strength Cond Res.16(1):44-9.

Moreno LA, Leon JF, SeronR, Mesana MI \& Fleta J (2004). Body composition in young male football (soccer) players, Nutr Res, 24:23542.

Poyraz A \& Demirkan AÇ (2011). Comparison of some physical and physiological parameters of turkish, austrian, belgian and hungarian international female athletes participated in european badminton team championship. Selçuk Unıversity Journal Of Physical Education And Sport Science, 13 (3): 330339.

Ryan ED, Everett KL, Smith DB, Pollner C, Thompson BJ, Sobolewski EJ \& Fiddler RE.(2014). Acute effects of different volumes of dynamic stretching on vertical jump performance, flexibility and muscular endurance. Clinical physiology and functional imaging, 34(6), 485-492.

Şerefoğlu A (2016). The effects of static and dynamic stretching exercises on antagonist muscle strength and electromiographic activity in agonist muscle, Tipta Uzmanlik Tezi, Uludağ Üniversitesi, Bursa

Sotiropoulos K, Smilios I, Christou M, Barzouka K, Spaias A, Douda H \& Tokmakidis SP (2010). Effects of warm-up on vertical jump performance and muscle electrical activity using half-squats at low and moderate intensity. Journal of Sports Science and Medicine, $\quad$ 9: 326-331. 
Saoulidis J, Yiannakos A, Galazoulas C, Zaggelidis G, Armatas V. (2010). Acute effect of short passive and dynamic stretching on $20 \mathrm{~m}$ sprint performance in handball players, Physical Training, 11; 610 .

Thomas D (2016). Erdman, K.; Burke, L.M. Nutrition and athletic performance. Med. Sci. Sports Exerc. 28: 105-115.

Tsunawake N, Tahara Y, Yukawa K, Katsuura T, Harada H \& Kikuchi Y (1995). Characteristics of body shape of female athletes based on factor analysis. Journal of Physiological Anthropology and Applied Human Science, 14: 55-61.

Turan S, Çilli M (2016). Farklı Isınma Yöntemlerinin Olimpik Okçulukta Atış Performansına Etkisi, Online Türk Sağlık Bilimleri Dergisi, 1(1), 13-0.

Ugarkovic D, Matavulj D, Kukolj M \& Jaric S (2002). Standard anthropometric, body composition, and strength variables as predictors of jumping performance in elite junior athletes. J. Strength Cond. Res. 16: 227-230. [CrossRef] [PubMed]

Ünlü SS (2008). Acute effects of combined heating applications on anaerobic power performance. Institute of Social Sciences, Department of Physical Education and Sports Teacher Education, Yüksek Lisans Tezi, Sakarya, Sakarya Üniversitesi; 61-63.

Üstündal KM \& Köker H (1998). How to earn sporda high performance, Nobel Tip Kitabevleri, s: 88,91,93,99, Ankara.

Zorba E (2005). Methods of measuring body structure and coping with obesity. Morpa Kültür Yayın Ltd. Ş., Yaylacık Matbaası, İstanbul, 39-221. 